\title{
The LC-NC Connection
}

\author{
Norman D. Stevens
}

\begin{abstract}
"Our inventions are wont to be pretty toys, which distract our attention from serious things. They are but improved means to an unimproved end, an end which it was already but too easy to arrive at. We are in great haste to construct a magnetic telegraph from Maine to Texas but Maine and Texas, it may be, have nothing important to communicate."

(Henry David Thoreau)
\end{abstract}

\section{Press Release}

The North Carolina State Library announces the introduction of The LC-NC Connection. This new high technology information system will make available to all of the citizens of North Carolina, through their local library, a wealth of information to assist them in every aspect of their lives. (April 1, 1990)

\section{Introduction}

Noted since 1963 for its imaginative approach to the most serious problems facing librarianship, The Molesworth Institute continues to research such problems as commissioned by appropriate bodies or as arcane problems come to its attention. In the past it addressed such mundane collection development issues as "Negative Library Growth," but of late it has addressed the more glamorous issues of technology such as "Imaginative Terminal Design for Online Public Access Catalogs."2 Flattered by the request to reprint some of its pioneering work in North Carolina $\mathrm{Li}$ braries, the director of The Molesworth Institute asked the editor what pressing issues now faced North Carolina libraries that might be researched by his staff. She suggested that the question of how to reconcile the rapid development of a statewide telecommunications network with a low and potentially declining literacy rate might truly

Norman Stevens is Director of the Molesworth Institute in Storrs, CT. challenge even our research skills. Equal to any challenge, the staff quickly retrieved Henry David Thoreau's comment on the relationship between technology and content and used that as the basis for an unusual brown earth session which led to the development of the LC-NC Connection that has been introduced by the North Carolina State Library. As the first system of this kind, the LC. NC Connection should serve, as the research of The Molesworth Institute typically does, as a model for others to follow or ignore at their peril.

\section{Some Fundamental Laws of Information}

The development of the LC-NC Connection is based primarily on a careful analysis of Thoreau's prescient comment and the following critical laws of information that were identified in the preliminary stages of this research project.

Boorstin's Law of Aliteracy: People who can read don't.

Cameron's Law of Urgency: The perceived need for information is directly proportional to the speed with which it is transmitted even if it is not needed immediately.

Cardew's Law of the Value of Informa. tion: Information supplied through a technological device is perceived to have a value twice as great as information supplied from a printed source.

Govan's Law of the Utility of Information: Any piece of information is of value to almost anyone.

Molesworth's Law of Equal Access to Information: All citizens of a state need equal access to information regardless of whether they can, do, or will make use of that information.

Pearson's Law of Information Storage: Eighty percent of the information that is supplied in the form of photocopies or computer printouts is stored, not read.

Stevens' Law of Machine Use: People will punch the buttons on a machine even if they don't know what they are doing. 


\section{The LC-NC Connection}

The LC-NC Connection is a simple device with several unusual features that, in essence, offers users the appearance of a highly sophisticated information system. Each participating library has available in a prominent location the simplest computer keyboard and display screen ever devised with programs that are run by the simplest software imaginable. The keyboard has only the twenty-six letters of the alphabet--although a cyrillic keyboard model is being developed and a single large clearly labeled enter key. There are no number keys, no shift, lock, tab, backspace keys; there are no function or other special keys; there is not even a help key. The screen carries only the following straightforward message: Please type your request and press the enter key. The user is free to enter whatever information he/she chooses in whatever form he/she chooses. As the enter key is pressed, or thirty seconds after the last letter key is pressed, the machine makes appropriate noises and the requested information appears from one of two devices located at either side of the terminal. One side issues photocopies and the other side computer printouts that may contain either bibliographic entries or full text material. Thus the user enters a simple request and almost instantaneously obtains information to take away. Cameron's Law of Urgency and Cardew's Law of the Value of Information mean that the products distributed in this fashion are readily accepted as being of substantial value.

The key to the simplicity is that the entry of the information has nothing to do with the information that is supplied. Instead the information is supplied at random from an accumulation of the numerous discarded photocopies or computer printouts that now litter most libraries or, if demand is abnormally high, from materials generated at random just for the system. What information is actually supplied makes little difference given the combined application of Boorstin's Law of Aliteracy, Govan's Law of the Utility of Information and Pearson's Law of Information Storage.

At the same time, the entire process satisfies Molesworth's Law of Equal Access to Information, and intensive use of the system by a broader range of citizens is guaranteed by Stevens' Law of Machine Use.

Analysis to date has indicated that eighty percent of the users of the LC (low cost)-NC (no content) Connection describe themselves as being highly satisfied with the results of their searches which is a user satisfaction level that rivals or exceeds that provided by more traditional library services.

\section{References}

1. Norman D. Stevens, "Negative Library Growth," The $U^{*} n^{*} a^{*} b^{*} a s^{*} h e^{*} d$ Librarian 13 (Fall 1974): 6

2. Norman D. Stevens, "Imaginative Terminal Design for Online Public Access Catalogs," Information Technology and Libraries 8 (March 1989): 69-71.

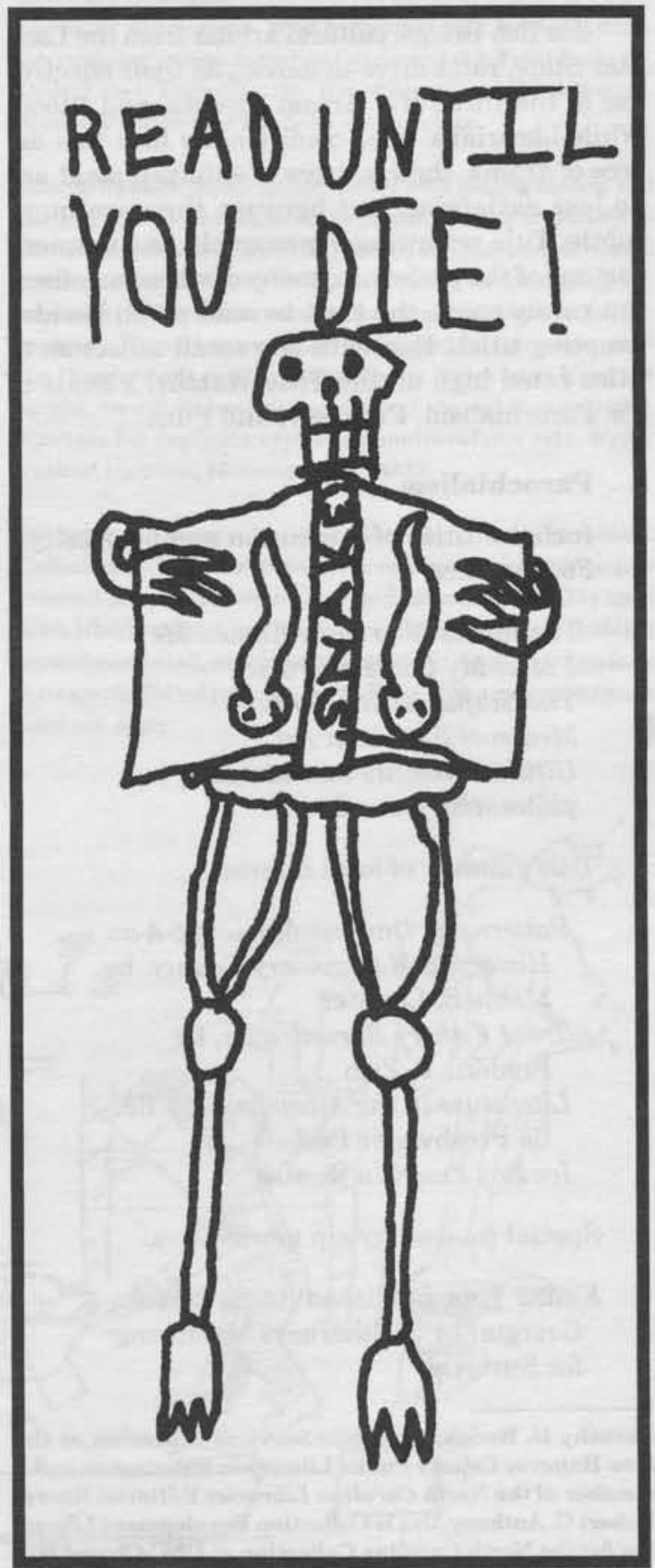

